\title{
Glimpses of Utopia Near Death? A Rejoinder
}

\author{
Allan Kellehear, Ph.D. \\ La Trobe University
}

ABSTRACT: Five scholars have offered comments, suggestions, and criticisms of my paper "Near-Death Experiences and Pursuit of the Ideal Society." In this rejoinder, I reply to those comments and elaborate on aspects of my earlier paper. I discuss issues of methodology, epistemology, validity, logic, and other social considerations with respect to the plausibility of viewing some near-death imagery as utopian. I conclude with some reflections on the social character and study of the near-death experience.

Raymond Moody (1988) and William Serdahely (1989) have both recently asked why near-death experiences (NDEs) intrigue us. Their answers point to spiritual perspectives, focusing as they do on the issue of personal survival of death. One of my aims in the essay "Near-Death Experiences and the Pursuit of the Ideal Society" was to develop a sociological answer to this question. My attempt was not aimed at rivaling the spiritual answers; rather it was based on the recognition that social influences may play a certain role in explaining the popular attraction of the NDE. NDEs are intrinsically tied to issues of personal and social identity; but those issues are not fully explained by analyzing the NDE as a physical or psychological crisis. There are social images in the NDE and some of these seem to have organizational features. Might these images play a role in the task of personal and social change?

Some of the problems with my argument had to do with problems

Allan Kellehear, Ph.D., is a Lecturer in the Department of Sociology at La Trobe University. Reprint requests should be addressed to Dr. Kellehear at the Department of Sociology, La Trobe University, Bundoora, Victoria 3083, Australia. 
that concern all near-death studies: their methods, their paucity of data, and the early, sometimes unsure development of enabling and useful theoretical frameworks. In this vein, I agree or am in sympathy with a good many of the reservations of my commentators. With other comments, I find that I am not in agreement, but space considerations restrict me to addressing only the main objections.

Carl Becker's characteristically thoughtful and provocative critique adopted three methodological approaches. First, Becker set about demonstrating the irrational worth of broad social values that may conflict with each other in practice. Positive social values implicit in the NDE are "motherhood" statements, statements whose characteristic lack of precision renders them "morally irrelevant." Becker felt that if he demonstrated how illogical and contradictory those values and images were, that somehow that would disqualify them from being viewed as utopian. That method should allow Becker to dismiss most, if not all, utopian writings, for few could survive such a technical review.

The problem with Becker's methodology in that instance was that the perceived worth or attraction of utopian images does not stem from their practical workability. Rather, utopian writings or ideas inspire people to practical experiment. It has quite often been true that those experiments have not worked out, but that did not lessen the attraction or make them less utopian in design. Just as importantly, this impractical side of utopian ideas does not lessen their potency in prompting social and personal change. I argue that this attraction is a factor in explaining the popularity of near-death imagery, logical and moral problems notwithstanding.

The second method Becker employed was to suggest a deterministic model of human nature: people are self-protecting, self-gratifying, and self-aggrandizing, and that pattern of relating plays no small part in the shaping of cultures. Becker could not accept that simply arriving at another culture could be critical to changing this incorrigible nature of humanity. I reject that culture-bound and essentialist notion of human behavior. Apart from broad genetic aspects of endowment, people are made social by their respective cultures. The social experiences one encounters by virtue of one's location in geography, society, and history contribute to the shape and priority of one's social and moral values.

By summarizing what is essentially an epistemological assumption of anthropological and sociological analysis, I am not dismissing individual differences. Nor am I arguing for a view of human nature that is infinitely and arbitrarily changeable. I am, however, stressing that if one accepts that culture and social organizations play major roles in 
changing people, then that socialization process should continue its realization in the transcendent society.

Becker's third method of critique was to argue for the importance of death and limitation as incentives for moral and social development. Once again, according to Becker, utopias that jettison death do so at the risk of becoming morally irrelevant. This is because without the finiteness and urgency that death imposes on life there would be little incentive for major moral development. However, a review of the gerontological literature might convince Becker that there are worse things in the world than death.

Many old people would argue that isolation or dependency are worse than death; Mahatma Gandhi argued that poverty is worse than death; and until quite recently, quite a few East Germans argued that deprivation of freedom was worse than death. In many aboriginal societies, death is not surrounded by the bourgeois sentiment known only recently in the Western world (Aries, 1981). In those societies, death is viewed much as another type of life; and yet moral and social development occurs in those societies, as indeed they do in the old, the poor, and the imprisoned.

Few people who desire social and personal betterment do so because of the knowledge that they will die. People embrace various ideas about fairness, kindness, comfort, or tolerance because for many people those ideas create safety, stability, and dignity for themselves and those for whom they care. Sometimes, for some people, these values have meant self-sacrifice and death. But it is these values and their affirming functions to which death itself is subordinated, and not the reverse. I agree that historically this has meant more conflict than harmony. But that only reinforces my view that death, however wasteful as we see it, is afterall a rather ordinary and pedestrian incentive for moral and social development.

The "mind-generated" model Becker proposed reflected once again his essentialist notion of self: the mind, presumably an asocial agency, will generate a world without moral and social rules because its search will be for "meaning" and "enlightenment." This proposal places an artificial, nonrelational division between mind and culture. What cognitive materials would a mind use to construct a world in that state? What models would it employ and where will those models come from, if not from its previous social or societal experience?

Patricia Weibust raised a very interesting issue that I found quite challenging also. She asked whether we might treat the sociological issues of order, control, and change as questions, and whether our current social concepts needed revision in analyzing the transcendent 
society. I agree with her suggestions. The method Kathy Charmaz suggested in her commentary offered a starting point for this approach. Examining the narratives for explicit and implicit meanings and inductively developing the symbols and categories from those meanings would be a creative approach. The "structural-functional" appearance of my own analysis stemmed from the narratives described by Craig Lundahl (1981-82), George Gallup and William Proctor (1982), and B. Elder (1987). The presence of conflict and disorder was minimal in those accounts and, although that did arouse my sociological suspicions, I took the view that that functional and projected view probably enhanced the attractiveness of near-death imagery for many people.

The issue of validity I deliberately left unaddressed. I do believe that for this first analysis, at this stage, it was not relevant or necessary to deal with that question. Whether the images recounted by NDErs originate from their brains alone or from some empirical reality does not alter the content features of the imagery. And it is this image content that interests me and many others around the world. I will address the emic/etic issue further below.

Howard Mickel believed I wrote about the transcendent society as if there were no variations or cultural diversity in that area. I can only say here that that was simply untrue. I advise that he re-read that section of my essay in which I did acknowledge other societies and I made particular mention of Chinese, Melanesian, and Indian ones. In that connection, I specifically mentioned the work of Satwant Pasricha and Ian Stevenson (1986), work that Mickel alleged I omitted.

In general, however, with regard to culture-specific features of the NDE, Mickel and I do not disagree. His comments broadly corresponded to my own conclusions in that area. Nevertheless, cultures that produce bows and arrows are not necessarily any less attracted to the values of order, education, and human service than other cultures that produce cities and libraries. Mickel's complaint that Indian cases of mistaken identity revealed flaws in the well-organized workings of transcendent societies was really a criticism of quality rather than substance. The fact that some utopias look less than ideal does not disqualify them from being utopian. That is because, as I have said, the criteria for utopian societies lie in their organizational approach to the problem of social and moral development, and not solely in any successful portrayal of perfection.

Mickel also wrote that I misrepresented Melanesian NDEs and, to support that claim, produced part of a Melanesian account I omitted. I 
did "ignore" that part of Dorothy Counts' (1983) work, because she herself classified that narrative as a Melanesian dream, not an NDE. My analysis did not include utopian imagery in dreams. I had also not sought to analyze the "cultural roots of Mormonism" because I had not analyzed any NDE account from Lundahl that was not consistent with those from Gallup, Elder, or Moody. As Lundahl argued in his original paper (1981-82), the accounts themselves were consistent with the piecemeal accounts from the near-death literature.

I do not agree that NDEs are the "special province" of religious studies, or any other discipline for that matter. Arguments about intellectual territory are usually covert ideological ones and in that sense spurious. Mickel referred to "Kellehear's program" as a "quasireligious quest." I have no program and my intellectual intention, if that was what was meant, was certainly not "quasi-religious." Concepts of death are social. NDEs occur in society and one important way of analyzing them is to adopt a social way of seeing and examining them. My aim, therefore, was to suggest one further reason, beyond the simple one of being attracted to the prospect of survival, that might account for the popular interest in NDEs.

In this context, Antonia Mills suggested that it is the feelings and the calmness of the NDE that capture the popular imagination more than the social images. I agree that those are indeed a contributing factor. I would add the qualification that feelings are about something, and that something is usually environmental. Feelings occur in contexts of some sort, and those contexts are sometimes described by NDErs in some detail. I also agree that the concept of utopia applies mainly in state societies, and is therefore a notion that is culturebound. Nevertheless, Westerners' interpretation of these social images, whatever their source, may be utopian, because that is a ready way for them to handle societal images. I readily acknowledge the limits of this comment for nonWestern NDErs and nonNDErs.

Charmaz wrote that I gave an interpretive rendering of the transcendent society, but one not well grounded in the data. This echoed Weibust's remarks concerning the emic/etic dilemmas in social research. There can be no doubt that an important part of understanding the social is to attempt to appreciate experience from the experiencer's point of view, that is, phenomenologically. On the other hand, that view itself is limited by the social positions of the various experiencers. Outsiders' interpretations, historical and social theories, have been developed to interpret beyond the individual's experiences so as to relate the different orbits of social life to one another. The task of 
"making sense" is more than simply adding the sum of all individual experiences. Unfortunately, outsiders' interpretations frequently suffer from problems of validity, as Weibust rightly noted.

In my essay, I was concerned not only about NDErs but just as importantly about how nonNDErs might make sense of social images derived from the NDE. I chose mainly Western NDE literature because the popular and media interest in the NDE to date has been Western. In this sense, I wrote and reflected not simply as a sociologist, but also as a thinking and reflecting nonNDEr who was part of that popular and widespread interest. In a methodological sense, then, part of the emic is the nonNDEr perspective, and I wrote from that verstehen as much as from a particular sociological one.

Charmaz thought that my attempt was "overdrawn" and the cases used from Lundahl's article too modest, a point also made by Weibust and Mickel. Perhaps they were correct in that view. But I do not believe that the exercise distorted the testimony of the NDEr nor misrepresented what, even in this early stage, seem to be its social images. My argument may have been overdrawn because I did not wait long enough or search widely enough for that additional detail before embarking on what Weibust wittily called my "scouting expedition." But if I have been impatient, it has not been for more details of the transcendent society but for more critical discussion and debate about the social character of NDEs.

The generation of debate and discussion that an early project attracts can itself often provide a rich and diverse set of ideas and suggestions. Frequently it is that discourse toward which we look for an understanding and a perspective. And for this worthwhile and valuable exchange, I thank the editor and each of the five participating commentators.

\section{References}

Aries, P. (1981). The hour of our death. London, England: Allen Lane.

Counts, D.A. (1983). Near-death and out-of-body experiences in a Melanesian society. Anabiosis: The Journal of Near-Death Studies, 3, 115-135.

Elder, B. (1987). And when I die, will I be dead? [Radio broadcast]. Sydney, Australia: Australian Broadcasting Commission.

Gallup, G., and Proctor, W. (1982). Adventures in immortality: A look beyond the threshold of death. New York, NY: McGraw-Hill.

Kellehear, A. (1991). Near-death experiences and the pursuit of the ideal society. Journal of Near-Death Studies, this issue.

Lundahl, C.R. (1981-82). The perceived other world in Mormon near-death experiences: A social and physical description. Omega, 12, 319-327. 
Moody, R.A. (1988). The light beyond New York, NY: Bantam.

Pasricha, S., and Stevenson, I. (1986). Near-death experiences in India: A preliminary investigation. Journal of Nervous and Mental Disease, 174, 165-170.

Serdahely, W.J. (1989). Why near-death experiences intrigue us. Journal of Near-Death Studies, 7, 149-153. 